Federal Reserve Bank of Minneapolis

Quarterly Review

Fall 1980

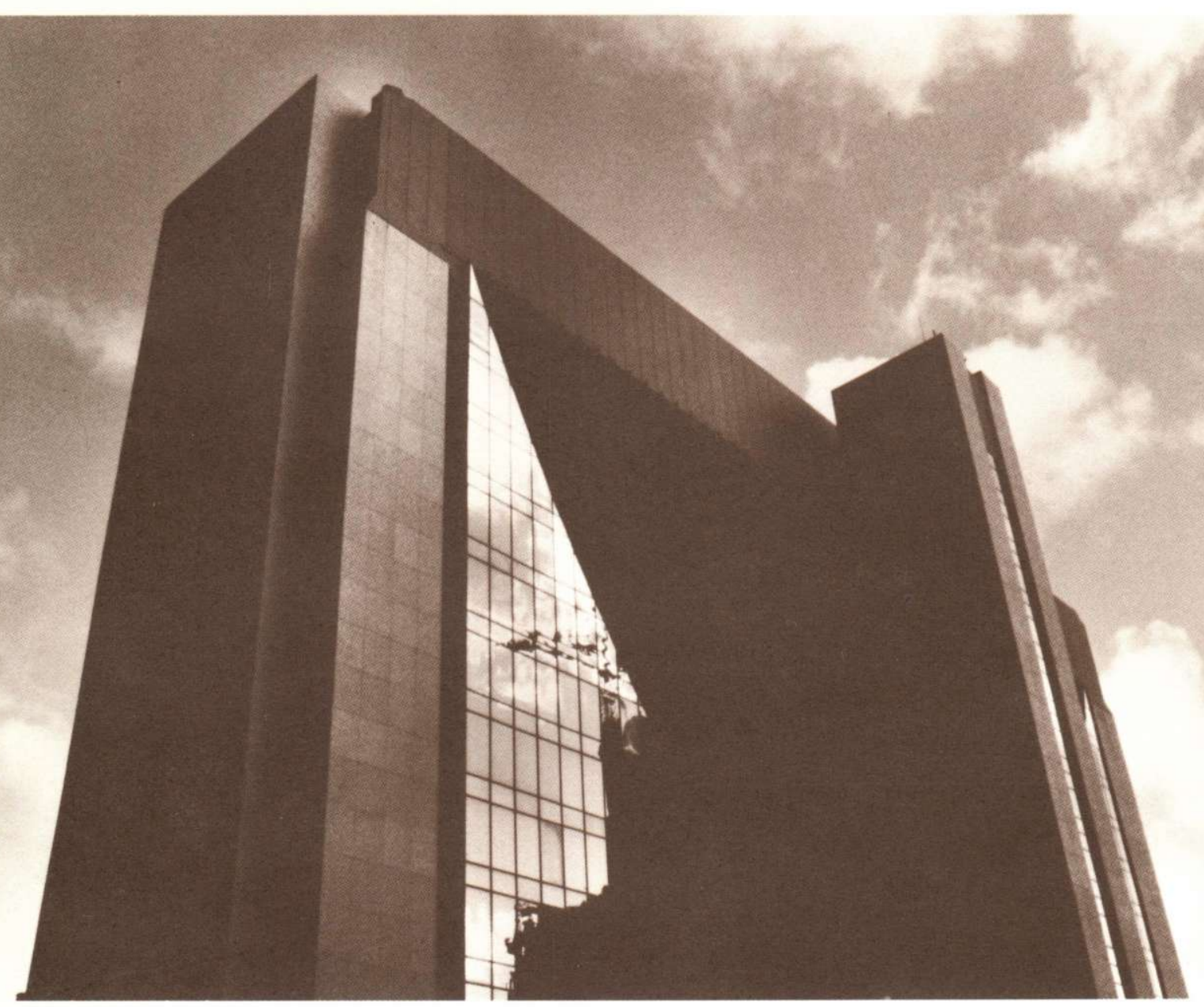

A New Approach to Monetary Control (p. 1)

Supply-Side Tax Cuts:

Will They Reduce Inflation? (p. 6)

Integrating Micro and Macroeconomics: An Application to Credit Controls (p. 16)

District Conditions (p. 30) 
Federal Reserve Bank of Minneapolis Quarterly Review vol. 4, No. 4

This publication primarily presents economic research aimed at improving policymaking by the Federal Reserve System and other governmental authorities.

Produced in the Research Department. Edited by Arthur J. Rolnick, Kathleen S. Rolfe, and Alan Struthers, Jr. Graphic design and charts drawn by Phil Swenson, Graphic Services Department.

Address requests for additional copies to the Research Department,

Federal Reserve Bank, Minneapolis, Minnesota 55480.

Articles may be reprinted if the source is credited and the Research

Department is provided with copies of reprints.

The views expressed herein are those of the authors and not necessarily those of the Federal Reserve Bank of Minneapolis or the Federal Reserve System. 


\title{
Integrating Micro and Macroeconomics: An Application to Credit Controls
}

\author{
Neil Wallace, Adviser
}

Research Department

Federal Reserve Bank of Minneapolis

and Professor of Economics

University of Minnesota

There is today increasing dissatisfaction with the disjointed economic theory taught at virtually all colleges and universities. The theory is split between microeconomics and macroeconomics, or, in somewhat oldfashioned terminology, between relative and absolute price theory. Dissatisfaction with this split is not new; economists have long wanted to integrate relative and absolute price theory, but simply did not know how to do it. What has intensified dissatisfaction lately are theoretical developments that have begun to accomplish the integration. These developments extend microeconomic theory so that it can explain some macroeconomic phenomena and analyze some macroeconomic policies. This paper presents a simple version of one such theoretical development and applies it to the study of credit controls.

We study credit controls here primarily because their analysis illustrates so dramatically the advantages of using a model that integrates relative and absolute price theory. It does this because the unintegrated models or tools of analysis provided by the standard economics curriculum are so obviously deficient for the analysis of credit controls. To see this, consider how a student who has mastered the standard curriculum would go about analyzing the consequences of credit controls.

The student could try to apply the models taught in price theory or microeconomics courses. Such models treat credit controls as inhibiting trade between potential borrowers and lenders, or, equivalently, as inhibiting trade between present goods and future goods. They describe the consequences of such controls as being completely analogous to the consequences of restrictions on trade between any two goods. The models describe how borrowers and lenders are affected by controls and show that credit controls are not Pareto optimal; that is, there exist other arrangements that make everyone better off than they are under credit controls.

Such analyses seem, however, seriously incomplete. After all, the popular view of credit controls as an anti-inflation device is not even addressed; it cannot be since the price level does not appear in microeconomic models. In order to consider the price level effects of credit controls, the student must turn to the models taught in macroeconomics and money and banking courses. By manipulating them, the student could, perhaps, see why some view credit controls as a way to reduce inflation.

But having done all that, the student should not be satisfied and, indeed, ought to be confused. The microeconomic theory suggests that credit controls are a gratuitous interference in the operation of markets, an interference that could even make everyone worse off. The macroeconomic theory says that the controls could help combat inflation. Suppose they do. Does that mean that everyone benefits from imposing them? Even those borrowers and lenders micro theory says are hurt? Are some people both helped and hurt by credit controls?

Clearly, in order to coherently analyze the consequences of policies like credit controls, the student needs a model that incorporates features of both micro and macro or relative and absolute price theory. This 
paper describes one such model, a microeconomic model that, however, is rich enough to let us also study the price level. ${ }^{1}$ Within that model, we analyze credit controls against the background of different monetary and fiscal policies: first when there literally is no monetary and fiscal policy - indeed, no government currency and, hence, no price level; then against the background of a balanced budget and a fixed and unchanging stock of government-issued fiat currency; and finally when there is a government deficit.

When we are done, we will have analyzed credit controls in a model with government currency and a government deficit, a model which shows qualitatively how these controls affect people in different circumstances: holders of government currency, borrowers, and lenders. We may even have come to some understanding of why credit controls have been adopted as often as they have been. ${ }^{2}$

\section{Overlapping Generations and Competitive Loan Demand and Supply}

The crucial features of a model built to analyze the effects of credit controls are its demand and supply functions for assets. The important axioms that underlie these functions in the model presented below are that

1. Assets are valued only in terms of their payoffs.

2. Anticipated payoffs are the same as actual payoffs.

3. Barring legal restrictions (like credit controls), no transaction costs inhibit borrowing and lending. ${ }^{3}$

Of these axioms, the first is, perhaps, the most important. It says that the demand for assets is a derived demand. Assets are not wanted per se, but only because of what they allow individuals to accomplish. Simply put, they are wanted because they let people convert income received in one time period into spending in a different time period. Policies like credit controls affect individuals by altering the terms on which they can accomplish such conversions. It is by strictly adhering to the first axiom that we are able to trace back to individuals all the effects of credit controls.

The second axiom is a perfect foresight, or rational expectations, axiom. In a model with assets, what happens today depends on what people think will happen to asset prices in the future. The second axiom is a defensible way of pinning down such views. It says, in effect, that expectations about the future are always realized.

The third axiom, the absence of transaction costs, implies that default-free private loans are perfect substitutes for default-free government liabilities, including currency, except insofar as legal restrictions inhibit the substitution of one for the other. Since credit controls are the only legal restriction considered in this analysis, default-free private loans and currency are treated as perfect substitutes except when certain kinds of credit controls are in effect. One interpretation of this treatment is that without legal restrictions, intermediaries costlessly convert default-free private loans into intermediary liabilities - bank notes or similar payment instruments - that the public considers perfect substitutes for government-issued currency.

Although critical, these three axioms are not, by themselves, a complete model. Our first task, therefore, is to describe a complete model, one consistent with these axioms and rich enough to allow us to address the effects of credit controls. The following variant of a model introduced by Samuelson satisfies these requirements. ${ }^{4}$

The economy is peopled by overlapping generations which live two periods each. At each date $t$ (where $t$ is an integer) a new generation-generation $t$-appears. Members of generation $t$ are in this economy at $t$ and $t+1$ only. Thus, at any date $t$, the population consists of the members of generation $t-1$ (who are old at $t$ ) and the members of generation $t$ (who are young at $t$ ).

At each date, only one good exists. The good that exists at date $t$ is called the time $t$ good. Each member

1The analysis may be fairly demanding for some readers. It requires familiarity with the material presented in an intermediate level (relative) price theory course.

2 Credit controls have been in effect temporarily several times in the United States, but are more prevalent abroad. They seem, for example, to be almost permanent fixtures in the post-World War II economies of the United Kingdom, France, and Japan.

3For a defense of these axioms - particularly the third, which is the most controversial - and for the application of a model consistent with them to the study of monetary policy, see John Bryant and Neil Wallace, A suggestion for further simplifying the theory of money, Research Department Staff Report 62, Federal Reserve Bank of Minneapolis, Minnesota (1980).

4See Paul A. Samuelson, An exact consumption-loan model of interest with or without the social contrivance of money, Journal of Political Economy 66 (December 1958): 467-82. 
of generation $t$ has preferences over lifetime consumption bundles consisting of some amount of the time $t$ good and some amount of the time $t+1$ good. We represent such preferences by an indifference curve map of the kind shown in Figure 1. Any combination of time $t$ and time $t+1$ goods is on some indifference curve (even though we have shown only some of the curves). The individual member of generation $t$ is indifferent among bundles on the same indifference curve and prefers bundles on higher indifference curves (in the direction of the arrow) to bundles on lower indifference curves.

Each member of generation $t$ also has an endowment of the time $t$ good and the time $t+1$ good, denoted $w_{i}^{j}(t)$ and $w_{i}^{j}(t+1)$, respectively, for member $j$ of generation $t$. We assume that these goods cannot be produced by anything else, and, in particular, that the time $t$ good cannot be used to produce the time $t+1$ good, say, by way of storage. In other words, unless member $j$ engages in some sort of trade, she or he is stuck with the endowment as a lifetime consumption bundle.

In order to generate borrowing and lending, we impose some diversity within generation $t$. But to keep things simple, we do this in a very particular way. Every member of generation $t$ has the same preferences, the same indifference curve map, but different members have different endowments: some members, who we call lenders, have a common endowment heavily weighted toward the time $t$ good, while the rest, who we call borrowers, have an endowment heavily weighted toward the time $t+1$ good (see Figure 1). These different endowments provide a basis for intertemporal trade (borrowing and lending) between members of the two groups.

Also, for simplicity, we assume that this withingeneration diversity is the only diversity. Thus, we assume that the composition of different generations regarding preferences and endowments is unchanging. That is, the preferences and endowments of the members of any single generation are identical to those of any other generation.

Now we must describe competitive desired trades of the time $t$ good and the time $t+1$ good by lenders and borrowers at various terms of trade. We denote these terms of trade by the symbol $R(t)$, where $R(t)$ is the price of the time $t$ good in units of the time $t+1$ good. Equivalently, $R(t)$ is the discount factor for
Figure 1

The Preferences and Endowments of Borrowers and Lenders in Generation $t$

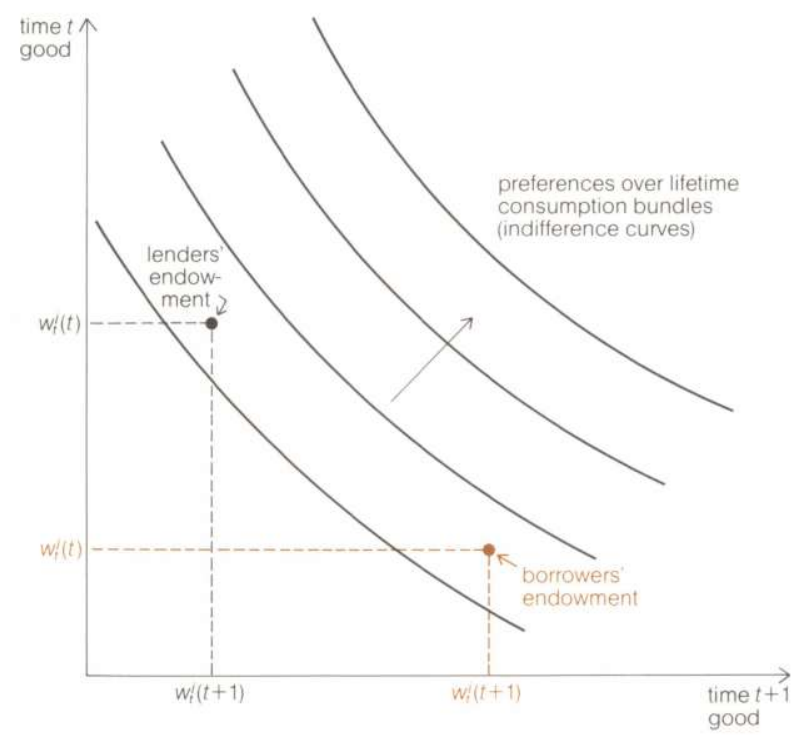

computing the time $t$ present value of the time $t+1$ good; thus, time $t$ wealth of member $j$ of generation $t$ in units of the time $t$ good is $w_{t}^{j}(t)+\left[w_{t}^{j}(t+1)\right] / R(t)$. [The reader should think of $R(t)$ as the gross real rate of interest, gross because it is unity plus the real rate of interest.] We describe the trades lenders desire as a market supply curve of the time $t$ good, or, equivalently, as a curve which describes the desired saving or lending of the group heavily endowed with the time $t$ good. We denote this supply curve by $S[R(t)]$ or $S(R)$ or $S$. We describe the trades borrowers desire as a market demand curve for the time $t$ good, or, equivalently, as a curve which describes the desired dissaving or borrowing of the group heavily endowed with the time $t+1$ good. We denote this demand curve by $D[R(t)]$ or $D(R)$ or $D$.

To find the $S$ curve, we first find the desired supply of the time $t$ good for one lender, then sum the desired trades over all the generation $t$ lenders. Figure 2 shows one lender's supply of the time $t$ good at a particular value of $R(t)$. The straight line is the upper boundary of all affordable bundles, the lender's budget set, implied by that value of $R(t)$. Given that the lender be- 
Figure 2

\section{A Lender's Supply of the Time $t$ Good Given $R(t)$}

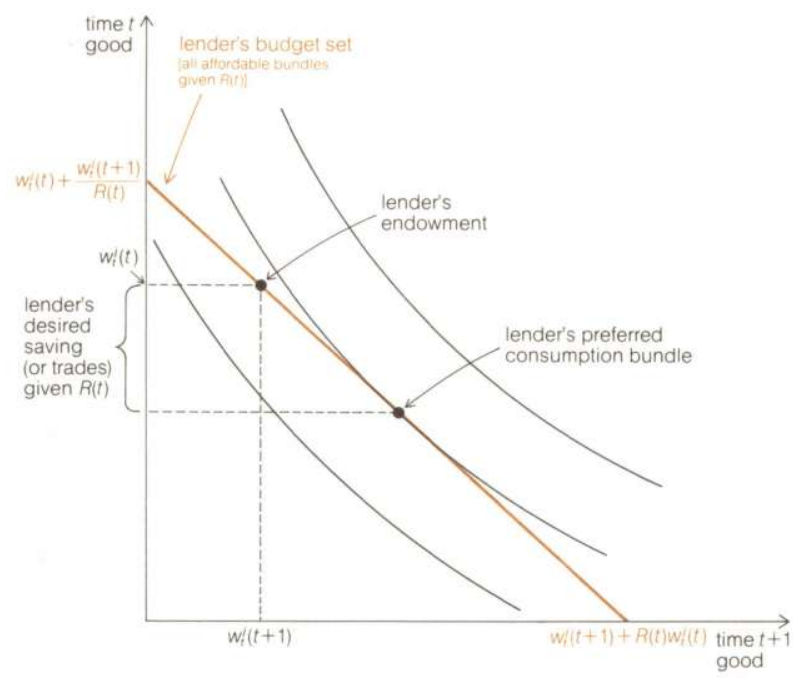

Figure 3

\section{Market Supply of and Demand for the Time $t$ Good}

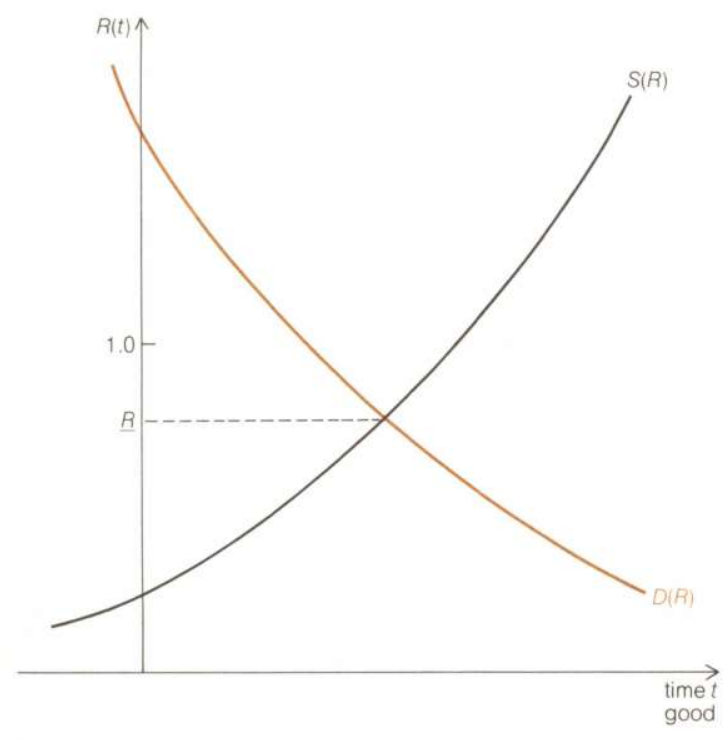

haves competitively, as a price taker, the supply of the time $t$ good by the lender at the particular value of $R(t)$ is the difference between the lender's endowment of the time $t$ good and the lender's preferred consumption of the time $t$ good at that value of $R(t)$. By facing the lender with different values of $R(t)$, we trace out how the individual lender's supply of the time $t$ good depends on $R(t)$. Since all lenders are assumed identical, the $S$ curve is simply the number of lenders in any generation, $N_{L}$, times the supply of the time $t$ good of the individual lender. To avoid possible complications not central to the points to be made, we assume that the $S$ curve slopes upward, as shown in Figure 3.

The $D$ curve, assumed to slope downward, is obtained in an analogous fashion. ${ }^{5}$

Given the assumption that different generations are identical, the $S$ and $D$ curves in Figure 3 describe competitive desired saving of lenders and dissaving of borrowers in every period. Notice that these curves intersect at a value of $R(t)$ less than unity or at a negative real rate of interest. This is what allows this model to be consistent with valued fiat currency in the absence of legal restrictions of any kind. One way of fulfilling this negative real interest rate condition is to have the number of lenders be sufficiently greater than the number of borrowers.

In succeeding sections, we will use the $S$ and $D$ curves and variants of them to study how the competitive equilibrium for our model depends on institutional arrangements - whether or not there are credit controls and the nature of such controls, whether or not there is fiat currency, and whether or not there is a government deficit. We think of ourselves as standing at the current date (for convenience, labeled $t=1$ ) and asking how the economy will evolve from this date on into the indefinite future under various institutional arrangements or policies we could adopt, assuming that that evolution takes the form of a competitive equilibrium.

sFormally, if $u\left[c_{i}^{j}(t), c_{j}^{j}(t+1)\right]$ is the utility function where $c_{i}^{j}(t+i)$ is consumption of time $t+i$ good by member $j$ of generation $t$, then $S[R(t)]=N_{L} s[R(t)]$, where $s[R(t)]$ is the solution for $w_{i}^{\prime}(t)-c_{i}^{j}(t)$ to the problem of maximizing $u$ subject to $c_{j}^{j}(t)+\left[c_{j}^{j}(t+1)\right] / R(t) \leq w_{j}^{\prime}(t)+\left[w_{j}^{j}(t+1)\right] / R(t)$, with $j$ being a lender. On the demand side, $\left.D[R(t)]=N_{B} d \mid R(t)\right]$, where $N_{B}$ is the number of borrowers in a generation and $d[R(t)]$ is the solution for $c_{i}^{j}(t)-w_{i}(t)$ to the same problem, but with $j$ being a borrower.

That $D(R)$ slopes downward follows from assuming that the time $t$ and time $t+1$ goods are not inferior goods. That $S(R)$ slopes upward requires that the substitution effect dominate the income effect. 
Notice that at $t=1$ the population of this economy consists of the members of generation 0 (the old) and the members of generation 1 (the young). While the preferences and endowments we have described and their implied $S$ and $D$ curves apply to young people at time 1 , they do not apply to those people who are old then. We assume that each old person at time 1 behaves competitively and attempts to maximize her or his consumption of the time 1 good. While this implies rather passive and simple behavior by the old at $t=1$, we do not want to ignore these people. Indeed, most of our analysis will involve a discussion of how three different groups fare: the old at $t=1$, lenders in the first and successive generations, and borrowers in the first and successive generations.

\section{Credit Controls in an Economy Without Currency}

We start with a purely relative price analysis of credit controls. We analyze the equilibrium for the model described above in the absence of fiat currency - first when there are no credit controls and then under costlessly enforced quantitative limits on how much each person may borrow. 6

The only trade that goes on at date $t$ is intertemporal trade among members of generation $t$. To see why, consider the situation of the members of generation $t-1$, the old at $t$. By assumption, each wants to get as much of the time $t$ good as she or he can. But in order for the old to trade for more than what they start with, they must give up something to the young at $t$, and the old have nothing to give up. The young would conceivably take a claim on the time $t+1$ good, but by assumption, the old have no such claim. (In the next section, they will have a potential claim in the form of fiat currency.) Here, therefore, to determine the equilibrium quantity of loans and the terms of trade, or the real interest rate, at any date $t$, we need only equate saving by generation $t$ lenders to dissaving by generation $t$ borrowers.

In the absence of controls, the relevant demand and supply curves are the $D$ and $S$ curves derived above (see Figure 3). The equilibrium is the intersection of those curves. Let's compare this solution with that under credit controls.

Consider a limit on the amount of the time $t$ good each member of generation $t$ may borrow. To get the demand for borrowing under this constraint, we must determine for each borrower a budget set that takes this constraint into account. Again we face each borrower with arbitrary terms of trade and ask what she or he would like to do, but now the implied budget set is as shown in Figure 4.

It follows quite generally that for all values of $R(t)$ less than or equal to some critical value, total desired borrowing (or dissaving) is at the limit. The critical value, denoted $\tilde{R}$ in Figure 5 , is the value of $R(t)$ at which borrowing is equal to the limit when there are no controls. Figure 5 shows the relationship between aggregate desired dissaving by borrowers with and without a constraint.

A limitation on each borrower does not change the amount of the time $t$ good lenders want to supply (in the region where that supply is positive). So the equilibrium under this sort of credit control is found by equating the unconstrained supply of the time $t$ good by lenders to the constrained demand for the time $t$ good by borrowers. Figure 6 shows the situation under a particular constraint.

The effects of a limit on borrowing are fairly straightforward. A binding limitation on borrowing hurts lenders and, depending on how stringent it is, may hurt or help borrowers. A sufficiently mild limitation, one that restricts borrowing to be only slightly less than what it would be without the constraint, helps borrowers because it imposes a solution that is in the direction of what would occur if borrowers acted jointly as a monopoly. However, a sufficiently stringent limitation, one that restricts individual borrowing to almost nothing, obviously hurts borrowers. Finally, binding credit controls of the sort we have examined are not Pareto optimal; given an equilibrium with binding credit controls, there exists an alternative assignment of the total endowment of the economy at each date that makes at least someone better off and no one worse off than in the credit control equilibrium. ${ }^{7}$

This completes our purely relative price theory analysis of credit controls. Notice that we have not used the dynamic, overlapping generations structure of our framework. The market analysis we have presented treats generation $t$ in isolation, as a separate two-good pure exchange economy in which the two

\footnotetext{
6For an analysis of the effects of a limit on lending, see Appendix A.

7Readers familiar with Edgeworth box diagrams should be able to prove this. Simply construct such a diagram using a borrower and a lender in generation $t$ as the two individuals with the dimensions of the box determined by the equilibrium consumption bundles under binding credit controls.
} 
Figure 4

\section{A Borrower's Demand for the Time $t$ Good}

Given $R(t)$ and a Limit on Borrowing

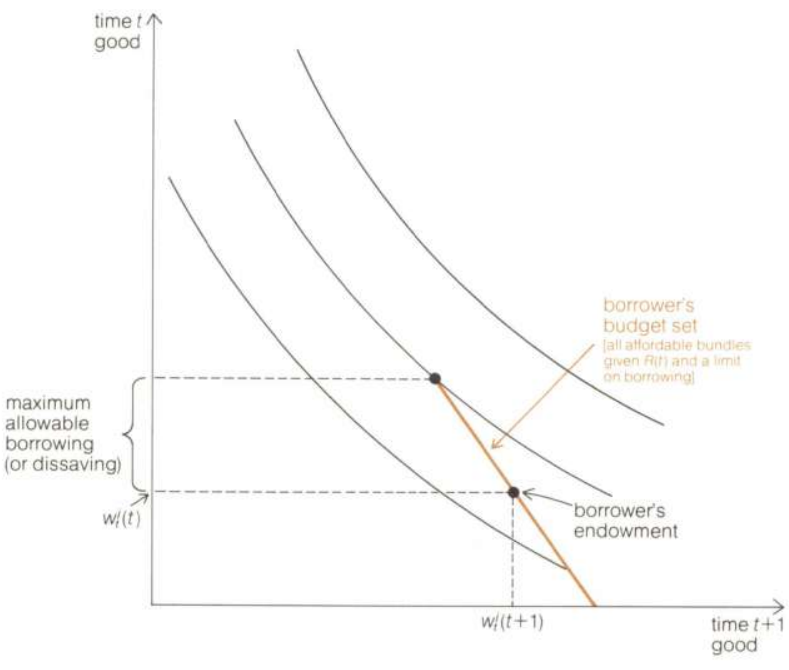

Figure 5

How a Limit on Borrowing Changes Market Demand for the Time $t$ Good

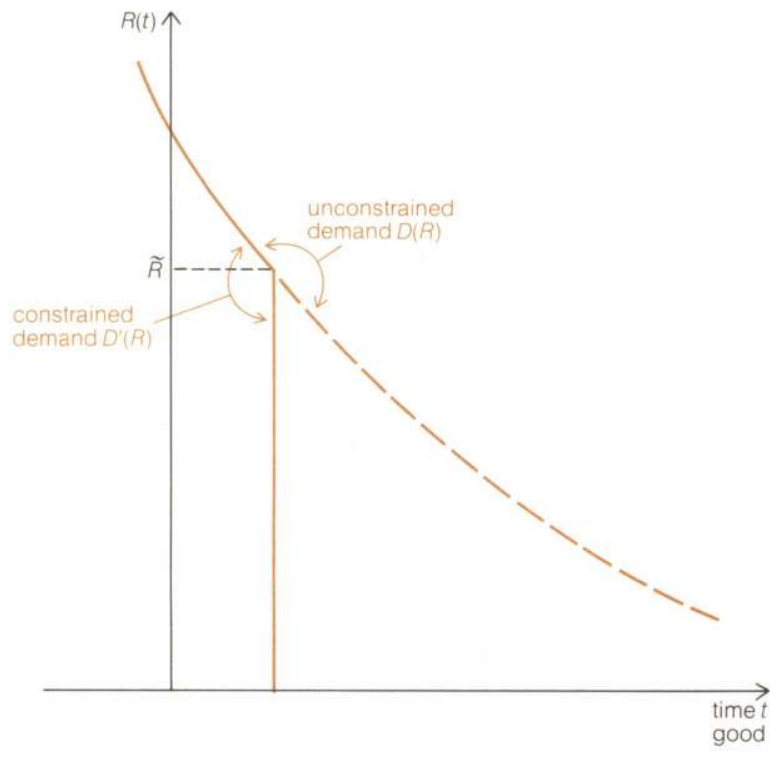

Figure 6

Market Equilibrium

With and Without a Limit on Borrowing

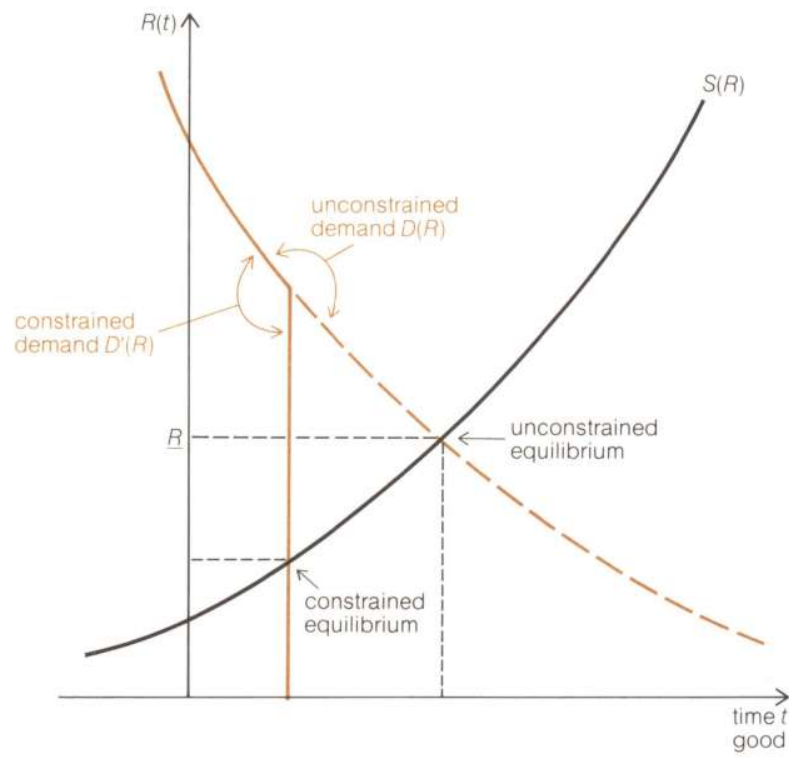

goods, which we labeled time $t$ good and time $t+1$ good, could have been labeled $x$ and $y$ or apple and orange.

Because this analysis has not addressed the absolute price level effects of credit controls, it may not be the whole story. Certainly, someone who advocated credit controls because of presumed beneficial effects on the path of the price level would not be willing to use it to appraise credit controls. Not that the analysis denies beneficial price level effects; it simply does not address them. We take a first step toward overcoming this omission in the next section.

\section{Credit Controls in an Economy With Currency and No Deficit}

The economy of this section is identical to that of the last, except that now the old at the initial date, $t=1$, own among them $M$ units of fiat or unbacked currency. Aside from having provided this stock of currency sometime in the past (or at $t=1$ ), the government is assumed to do nothing but impose or not impose credit controls. In particular, this government has a per- 
manently balanced budget.

The fiat currency owned by the old at $t=1$ is potentially a claim on goods at $t=2,3, \ldots$. This claim satisfies the old dictum about money that a person gives up goods for it only because that person expects to be able to subsequently exchange it for goods. In our model, this dictum takes the following form.

If fiat currency is to have value at every date (is to be worth something in terms of goods), then a young person in generation $t$, most likely a lender, must be willing to give up some of the time $t$ good in order to acquire some of the fiat currency. If the lender is willing to do that, it is because the lender expects to be able to exchange the fiat currency for goods at time $t+1$ by selling it to a member of generation $t+1$, again, most likely a lender of generation $t+1$. Yet that is not enough. If the lender is free to grant as many loans and buy as much currency as she or he wishes, then in order that both currency have value and loans be granted, some lenders must expect the rate of return on currency to be at least as high as that on loans, while others must expect the rate of return on loans to be at least as high as that on currency.

Obviously, the second of our initial axioms becomes important here. According to it, realizations never differ from previously held beliefs; thus, expectations about future values of currency turn out to be exactly right when the economy is in equilibrium. We will call an equilibrium of this sort a perfect foresight equilibrium.

The imposition of perfect foresight simplifies matters in several ways. It implies that lenders at time $t$ are unanimous, which, in turn, implies that if lenders are free to hold whatever portfolio they want and if currency and loans are both held in equilibrium, then the rate of return on currency will be the same as the rate of return on loans. Perfect foresight also suggests a shortcut to thinking about at least one equilibrium in which currency is worth something in every period. If that is to be true, then at each date all the old must offer all the existing currency for sale, it having been passed on to them from generation to generation. In other words, the quantity of currency supplied at each date is the same (namely, $M$ units), and it is offered at any positive price in terms of goods. The demand for currency at each date $t$ arises from the behavior of the members of generation $t$. Since they are exactly the same at every date, it makes sense to suppose that the demand for currency is too. And if the demand and supply schedules or functions are both the same at every date, then it makes sense to look for an equilibrium in which the price of currency, the value of each piece in terms of goods, is the same at every date. (Note that this is equivalent to saying that the absolute price level of goods in terms of currency - which is the inverse of the price of currency - is constant.)

For the economy we have described, in the absence of credit controls, there is, indeed, an equilibrium in which the price of currency is positive and constant. To demonstrate that, we must show that there is some price of currency $p>0$ such that when individuals face this price and the implied gross return of unity on currency in every period, then in every period the supply of currency equals the demand for currency and desired borrowing equals desired lending.

\section{Figure 7}

\section{Market Equilibrium in an Economy With Currency} and No Deficit or Controls

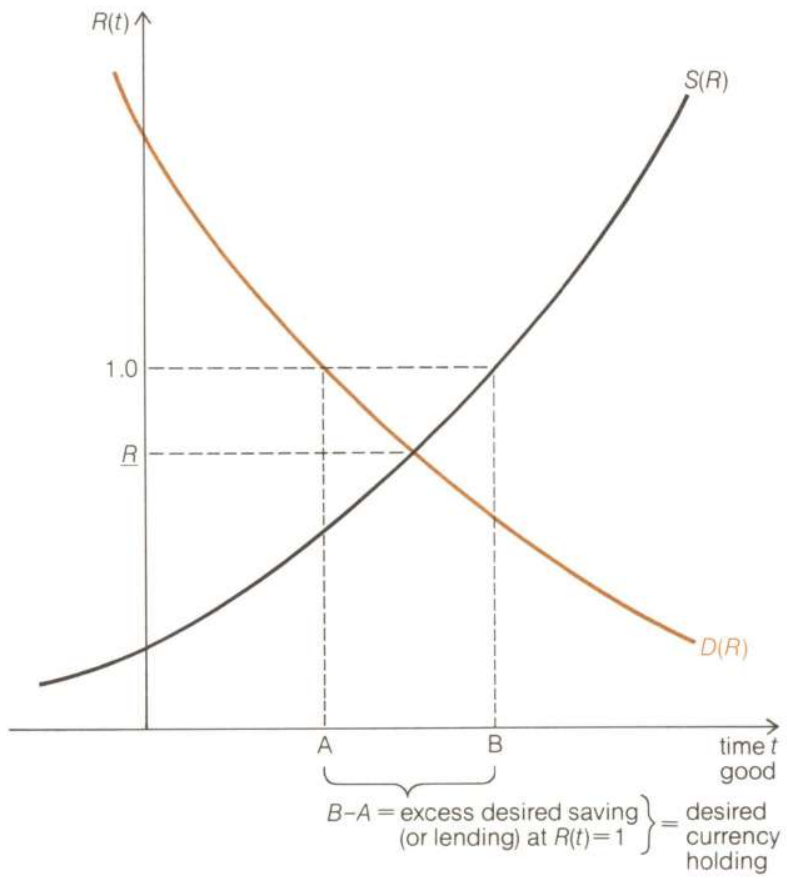


We proceed graphically, using Figure 7 (which is simply Figure 3 with some additional labeling). In Figure 7, the quantity $B$ represents desired saving (or lending) of lenders at $R(t)=1$, while $A$ represents desired dissaving (or borrowing) of borrowers at $R(t)=1$. Thus, $B-A$ represents the excess of desired saving over desired dissaving at $R(t)=1$. Our proposed unchanging equilibrium price of currency, $p$, is the one that makes the value of currency fill the gap between lenders' desired saving and borrowers' desired dissaving at $R(1)=1$; namely, $p=(B-A) / M$. We now argue that this constant price of currency and $R(t)=1$ for all $t \geq 1$ are part of a perfect foresight competitive equilibrium.

If $R(t)=1$ and the gross rate of return on currency is unity, then lenders want to save $B$ in every period. Moreover, since the return on loans is the same as that on currency, they do not care how much of each they have in their portfolios; any quantities of loans and currency whose value sums to $B$ is alright. In particular, if the amount of loans held is $A$, which is the amount borrowers want to borrow at $R(t)=1$, then $B-A$ is the value of currency lenders want to hold. Thus, we have equality between currency supply and currency demand and between loan supply and loan demand at $p=(B-A) / M$ and $R(t)=1$ [and an absolute price level of $M /(B-A)]$.

At any date $t$, in an equilibrium in this economy, generation $t$ lenders grant loans to generation $t$ borrowers and buy currency from members of generation $t-1$, the old at $t$. In terms of goods, in the aggregate they spend $B-A$ on currency and grant loans in the amount $A$ at $R(t)=1$. Lenders expect the gross return on currency to be unity and are not disappointed.

Several features of our economy are crucial for the existence of this type of equilibrium. The amount of currency in the system must be $M$ units in every period (an assumption that will be dropped in the next section). The $S$ and $D$ curves must be in the same position in every period, which follows from our assumption that generations are identical. And at $R(t)=1$, desired saving of lenders must exceed desired dissaving of borrowers.

Now consider what happens in this economy when the amount of borrowing by each borrower is permanently limited. Just as in the simpler economy without currency, lenders' aggregate desired supply is not affected by the control, and borrowers' aggregate demand
Figure 8

The Effect of a Limit on Borrowing on Market Equilibrium in an Economy With Currency and No Deficit

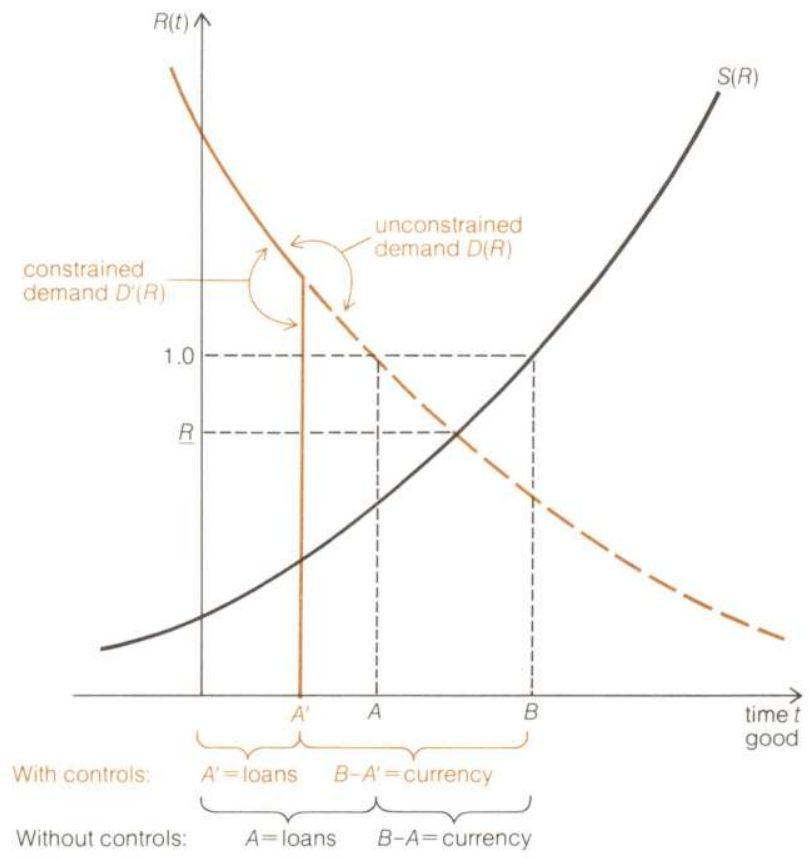

obviously is; it is derived exactly as before. Suppose it is as illustrated in Figure 8. Then there exists an equilibrium with $R(t)=1$ for all $t \geq 1$ and with a constant and positive price of currency given by $p=\left(B-A^{\prime}\right) / M$ [and a constant and positive absolute price level of $\left.M /\left(B-A^{\prime}\right)\right]$.

A comparison with the no-control equilibrium in Figure 7 is straightforward. Lenders are affected by the control, but only in the composition of their saving; because of the control, less is in loans and more is in currency. Borrowers still face a gross borrowing rate of unity, but they are constrained to borrow less than they would like to at that rate. Finally, the initial old at $t=1$ get more goods for their currency than in the absence of this kind of credit control.

There is quite a contrast between these consequences of a limit on borrowing and those in the last section. In the standard micro economy without cur- 
rency, remember, such a limitation could hurt everyone involved in borrowing or lending: borrowers might be helped or hurt, while lenders were always hurt. The initial old were not involved or affected. Here, with a fixed supply of government currency, however, the same limitation does not affect lenders, necessarily hurts borrowers, and necessarily benefits the initial old. Thus, although an equilibrium with binding credit controls is again not Pareto optimal, the fact that some individuals definitely prefer controls to no controls helps explain why there is support for such controls. As we now show, in an economy with a permanent government deficit, even more individuals prefer controls to no controls.

\section{Credit Controls in an Economy With a Permanent Deficit}

Here we assume that the government attempts to finance a permanent real deficit by currency creation. ${ }^{8}$ Again we compare what happens to members of the economy with and without credit controls.

For the government to get command over $G(t) \geq 0$ units of the time $t$ good by issuing additional currency at time $t$, it is necessary that

$$
G(t)=p(t)[M(t)-M(t-1)]
$$

where $p(t)$ is the price of currency in terms of goods at $t$ (again, the inverse of the price level at $t$ ) and $M(t)$ is the stock of currency held from $t$ to $t+1$ by members of generation $t .{ }^{9}$

For $t>1$ and $p(t)>0$ for all $t$, we may rewrite (1) as

$$
G(t)=p(t) M(t)-p(t-1) M(t-1)[p(t) / p(t-1)] .
$$

Let $m[R(t)]$ be the demand for real money holdings at time $t$. (As we saw above, in the absence of controls, $m[R(t)]=S[R(t)]-D[R(t)]$.) For equilibrium we require that $m[R(t)]=p(t) M(t)$ for all $t \geq 1$ and that $R(t-1)=p(t) / p(t-1)$ if currency is held. Substituting these equilibrium requirements into $(2)$ we get

$$
G(t)=m[R(t)]-m[R(t-1)] R(t-1) .
$$

We will assume that $G(t)=G \geq 0$, a constant for all $t$, and will look for an equilibrium with the property that $R(t)=R$, a constant for all $t$. By (3), such a value of $R$ must satisfy

$$
G=(1-R) m(R)
$$

where $1-R$ should be thought of as a tax rate and $(1-R) m(R)$ as a revenue curve or function. If we can find an $R$ that satisfies (4), then we find the corresponding price of money at $t=1$ from the $t=1$ version of (1), namely,

$$
G=p(1) M(1)-p(1) M(0)=m(R)-p(1) M(0) .
$$

With $R$ known from (4) and $M(0)$ given as an initial condition, (5) can be solved for $p(1)$. It also follows that $M(t) / M(t-1)=1 / R$, the gross inflation rate for all $t \geq 1$.

We first consider the situation without credit controls. In this case, as mentioned above, the function $m(R)$ is the horizontal distance between the $S$ and $D$ curves of Figure $3 ; m(R)=S(R)-D(R)$ for values of $R$ where $S(R)-D(R) \geq 0$. Figure 9 shows a hypothetical $(1-R)[S(R)-D(R)]$ function.

Notice that $R$ is the equilibrium return on loans of our simplest economy, without government currency or controls. Notice also that if $G$ can in fact be supported by currency issue in the absence of controls that is, if $G \leq G^{*}$ - then, in general, at least two values of $R$ (and tax rates $1-R$ ) are solutions. We will limit our attention to the solution for which $R$ is a maximum, the minimum tax-rate solution. In the situation depicted in Figure 9, this is $\hat{R}$.

The reader should be able to verify that $p(t+1) / p(t)$ $=M(t-1) / M(t)=\hat{R}$ for all $t \geq 1$ and $p(1)$ given by $(5)$ with $R=\hat{R}$ and $m(\hat{R})=S(\hat{R})-D(\hat{R})$ is a perfect foresight competitive equilibrium in which the government gets command over $G$ units of the time $t$ good at every date $t \geq 1$ (and the gross inflation rate is $1 / \hat{R}$ ).

In order to study financing of the same deficit under credit controls, we must replace $m(R)=S(R)-D(R)$ by $m(R)$ as given by the difference between possibly constrained supply and demand curves. Suppose again that the amount of borrowing by each borrower

$8 \mathrm{~A}$ temporary deficit and temporary credit controls are studied in Appendix B.

${ }^{9}$ We regard $G(t)$ as resources used to provide a public good - for example, national defense - and assume that the amount provided does not affect the way individuals rank alternative private lifetime consumption bundles. That is, the indifference curve map of Figure 1 does not depend on $G(t)$. 
Figure 9

Government Revenue in an Economy Without Controls

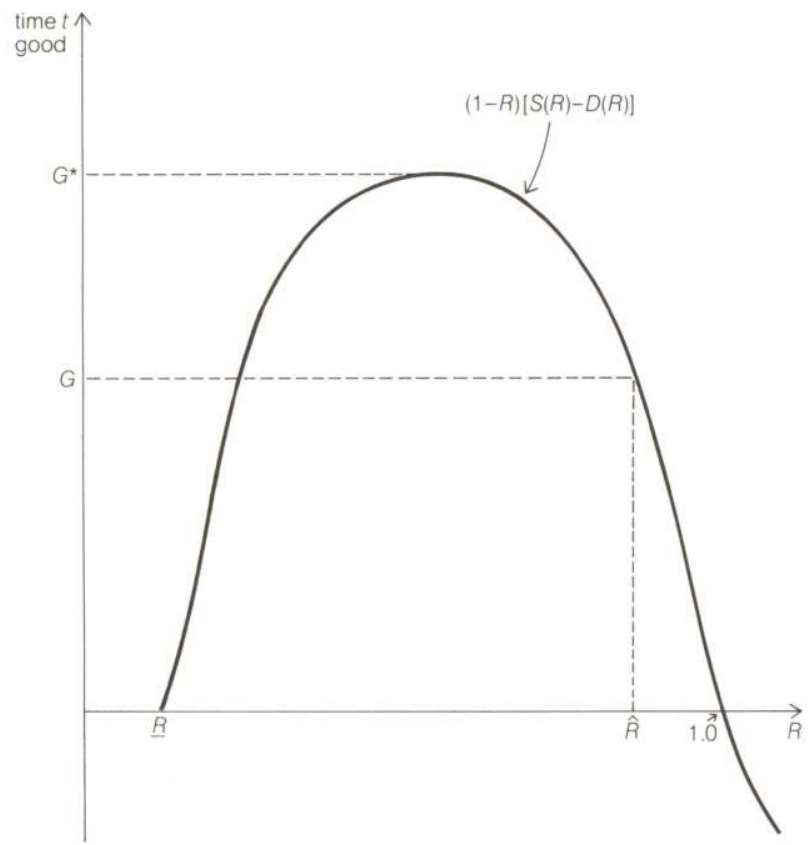

is limited and that this produces the desired dissaving curve of the last section (see Figure 8), a curve denoted $D^{\prime}(R)$. Since $D^{\prime}(R)<D(R)$ at each value of $R$ where $S(R)-D(R)>0$ and $R \leq 1$, the borrowing limitation produces a higher revenue function. (This is illustrated in Figure 10.)

It follows immediately that under such a limitation the deficit $G$ is consistent with a lower gross inflation rate $\left(1 / R^{\prime}\right.$ instead of $\left.1 / \hat{R}\right)$ and with a higher initial price of money [see equation (5)] than exist without controls. This, in turn, implies that lenders and the initial old prefer such controls to no controls and that the reverse is true for borrowers. Credit controls in an economy with currency and a permanent government deficit, then, help everyone except borrowers. Thus, although it is still true that any outcome with binding credit controls is not Pareto optimal, when the alter-
Figure 10

Government Revenue

With and Without a Limit on Borrowing

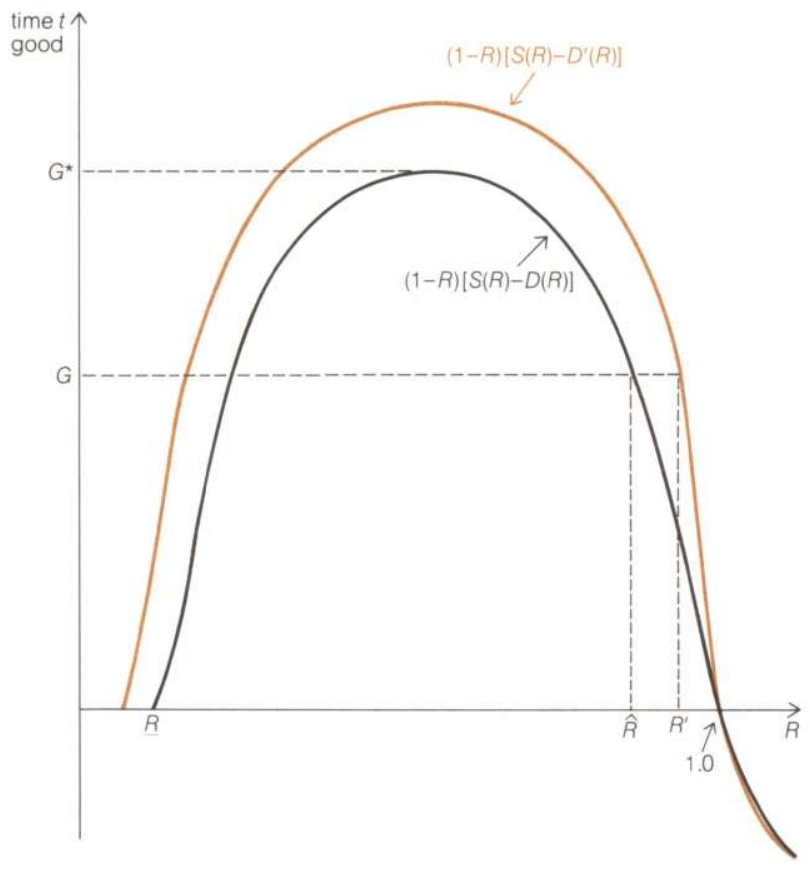

native to controls is no controls, most people prefer controls.

\section{Concluding Remarks}

It must be admitted that the kind of analysis of credit controls presented above represents, at most, a small step toward a satisfactory analysis. We have seen that every outcome with binding credit controls is not Pareto optimal: if we treat as attainable any outcome that does not exceed the total resources available, then at least one outcome exists that makes everybody better off than they are with binding credit controls. It seems doubtful, however, that all such outcomes are attainable. If they were, not only would we argue that credit controls are undesirable, we would predict that we would not observe them. We would also, by the way, predict that we would never observe use of a distorting tax, one that generates attempts to avoid it. 
Examples of such taxes are tariffs, excise taxes, income taxes, and the deficit assumed to exist in the last section. ${ }^{10}$ The obvious, if troublesome, conclusion is that we cannot oppose credit controls by appealing to their non-Pareto optimality in the set of outcomes that do not exceed the total resources. Yet to assume that the only options are market outcomes with and without controls is to assume that too few outcomes are attainable. For example, if quantitative controls on loans can be enforced, then it seems likely that a tax on loans can too. What seems to be needed, then, is a better model of the set of attainable outcomes than the one we have provided.

Despite this, the kind of integrated analysis that we have presented is clearly a substantial improvement over the analyses of standard economic theory. It should leave students considerably less confused. Instead of leaving them with the task of integrating the conclusions of separate relative and absolute price analyses, it provides students with a model that simultaneously displays both types of effects which policies like credit controls may have.

10 For a welfare analysis of a permanent deficit, see Neil Wallace, The overlapping generations model of fiat money, in Models of monetary economies, ed. John H. Kareken and Neil Wallace, Federal Reserve Bank of Minneapolis, Minnesota (1980): 49-82. 


\section{Appendix $A$ The Effects of a Limit on Lending}

\section{In an Economy Without Currency}

When there is no fiat currency, the analysis of a limit on the amount each lender can lend is analogous to that of a limit on borrowing. Lenders' constrained supply of the time $t$ good is derived and equated to borrowers' unconstrained demand. (Figure Al depicts the situation under a particular constraint.) Again in this simple economy, everyone involved can be hurt: borrowers always are and lenders may or may not be, depending on how stringent the lending control is.

\section{In an Economy With Currency and No Deficit}

When fiat currency is in the model but there is no government deficit, the analysis of the lending limit is not quite so analogous to that of the borrowing limit. A control on lending is somewhat more difficult to analyze. Notice that under this kind of control the return on loans may be higher than that on currency. In such a situation, even though every lender would like to switch from currency to loans, the quantitative restriction prevents them from doing so.

Figure A1

Market Equilibrium With and Without a Limit on Lending

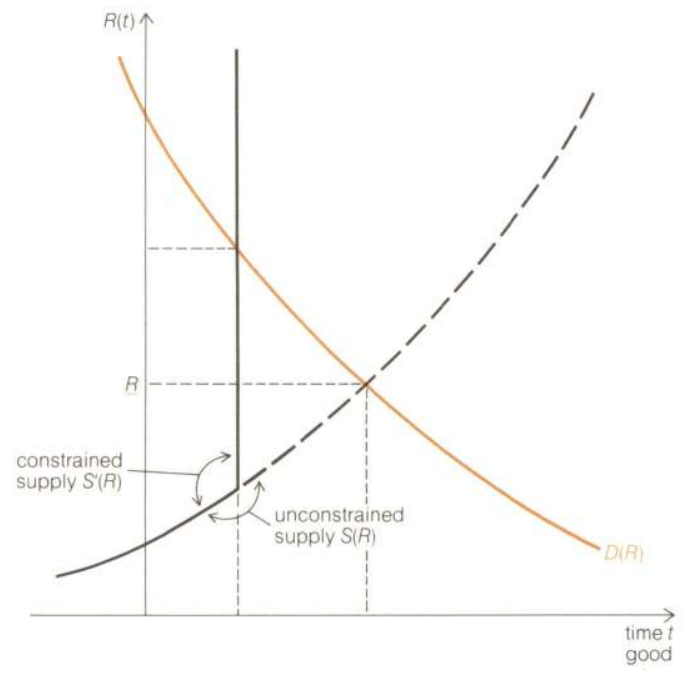

Suppose that each lender is restricted to saving no more than $L$ in the form of loans, where $N_{L} L<A, A$ being the amount lent in the equilibrium without controls depicted in Figure 7. (Recall that $N_{L}$ is the number of lenders.) Since borrowers are unconstrained, the gross rate on loans must be high enough to make borrowers demand only $N_{L} L$ amount of loans. This rate, denoted $R_{L}$, is found by consulting the $D(R)$ curve of Figure 7; that is, it is the solution to $D\left(R_{L}\right)=N_{L} L$. Obviously, with $N_{L} L<A, R_{L}>1$.

Now consider the budget set facing a lender under this kind of constraint, with a rate of return on currency equal to unity. Figure A2 shows such a budget set (along with that faced by a lender in the no-control equilibrium of Figure 7). Several conclusions may be drawn from studying the decision making of lenders faced with this kind of kinked budget set. First, lenders are better off under a constraint of this kind than they are in the no-control equilibrium. Second, total desired saving is less with a constraint than with $R(t)=1$ and

Figure A2

A Lender's Budget Set

With a Limit on Lending in an Economy With Currency and No Deficit

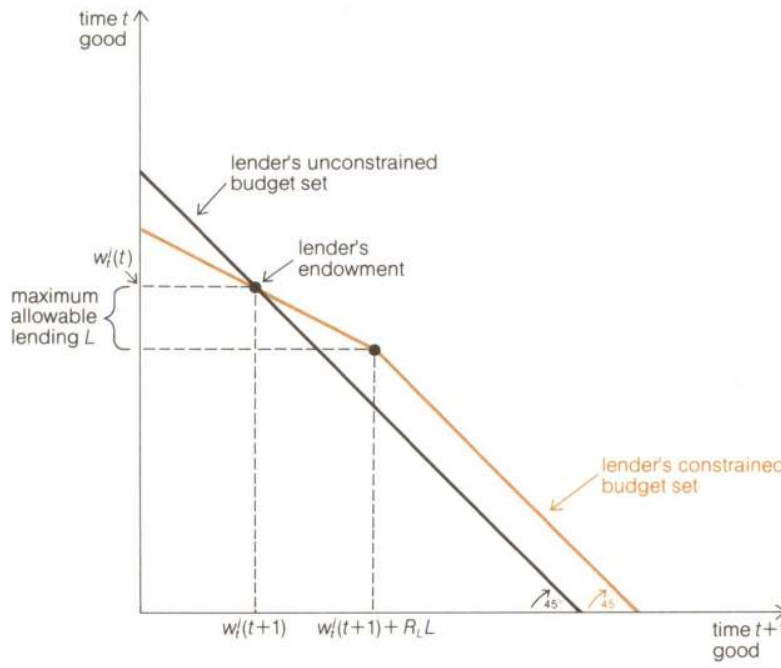


Figure A3

A Lender's Budget Set

With a Limit on Lending

in an Economy With a Gross Inflation Rate of $1 / R$

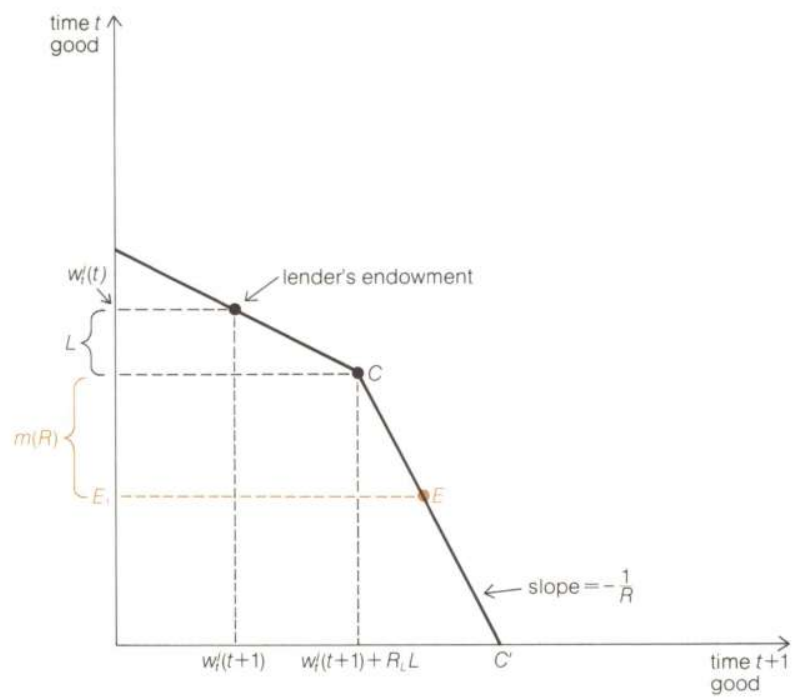

Figure $\mathrm{A} 3$ shows the budget set facing a lender under a particular restriction on loans, $L$, the implied $R_{L}$, and some rate of return on currency, $R$. It follows from our other assumptions that the preferred point on this budget set is somewhere on the line segment $C C^{\prime}$, possibly at $C$. If the preferred point is $E$, then the value of the relevant $m(R)$ function at the particular value of $R$ depicted in Figure A3 is $w_{t}^{j}(t)-L-E_{1}$. By considering various values of $R$, we can trace out the relevant $m(R)$ function.

The important conclusion from this analysis is that we cannot say for each value of $R$ whether the implied $m(R)$ function exceeds or falls short of $S(R)-D(R)$. Thus, unlike the situation with a restriction on borrowing, here we cannot order in any simple way the revenue functions with and without controls. Therefore, we cannot generally conclude that a given real government deficit can be financed at a lower inflation rate and a lower initial price level with this kind of control than with no control. However, if the lending limitation is stringent enough, such a conclusion does hold. In that case, both lenders and the current old prefer the situation with controls to that without controls. no constraint.* Third, desired saving in the form of currency may be greater or less than $B-A$ (see Figure 7).

Thus, the effects of a quantitative limit on the amount of lending by each lender are not clear-cut: borrowers are hurt and lenders are helped, but how the current old are affected is ambiguous. The ambiguity can be removed by making $L$ sufficiently small. In the extreme case of no lending allowed, the current old are necessarily benefited-but lenders no longer are. For sufficiently small amounts of allowed loans, though, saving in the form of currency and, hence, the price of currency are higher than in the unconstrained equilibrium. So when lending is limited to a sufficiently small amount, both lenders and the current old benefit.

\section{In an Economy With a Permanent Deficit}

When there is a permanent government deficit, the analysis of a limit on lending is no less ambiguous than without a deficit.

Suppose again that the limit is such that the rate on loans, $R_{L}$, which makes borrowers willing to borrow no more than the limit, exceeds unity. In this case, to find the relevant $m(R)$ function for equation (4), we only need to slightly generalize the approach described earlier.

*This follows if first-period consumption is not an inferior good. 


\section{Appendix $B$ Temporary Credit Controls}

The framework presented in the text can also be used to analyze a temporary imposition of credit controls given a temporary deficit. In the United States, at least, credit controls have usually been imposed as a temporary device, presumably to deal with a temporary situation like a temporary deficit.

We analyze only the following simple situation. The government attempts to raise $G$ units of the time 1 good by a new issue of currency at time 1 . Thereafter, forever, it runs a balanced budget, one consequence of which is $M(t)=M(1)$ for all $t \geq 1$. We compare the situation without credit controls only with that under a limitation on borrowing by each borrower and only at time 1 .

In the absence of credit controls, we look for the same kind of equilibrium found earlier in the economy with a balanced budget in every period. That is, we look for a positive and unchanging price of currency, $p$. Here, however, we replace the fixed and unchanging quantity of currency, $M$, by $M(1)$, which is the amount of currency available to be purchased by the young at time 1 , the sum of what the old at $t$ start with, $M(0)$, and what the government issues at $t=1$.

The quantities $p$ and $M(1)$ must satisfy two equations: $p M(1)=S(1)-D(1)$ and $p[M(1)-M(0)]=G$, where $S(1)$ and $D(1)$ are read off the curves of Figure 3 and $M(0)$ and $G$ are given parameters. If $G<S(1)-D(1)$, these equations can be solved for $p$ and $M(1)$. [Note that the second equation is equation (1), the government budget constraint, for $t=1$, while the first is the familiar condition that the supply of currency be equal to the demand for currency.]

We now compare features of that solution to those of the solution under a limitation on each borrower at $t=1$. We show that under such a limitation there is an equilibrium with a constant price of currency from $t=2$ on; in particular, an equilibrium with $p(t)=p(2)>p(1)>0$ for all $t \geq 2$.

As was true without controls, the quantity of currency is constant at $M(1)$ from $t=1$ on. The three quantities, $p(1)$, $p(2)$, and $M(1)$, must satisfy

$$
\begin{aligned}
& p(1) M(1)=S[p(2) / p(1)]-D^{\prime}[p(2) / p(1)] \\
& p(2) M(1)=S(1)-D(1) \\
& p(1)[M(1)-M(0)]=G .
\end{aligned}
$$

Here, (B1) expresses equality between the time 1 supply of currency and the time 1 demand for currency. The demand is given by the difference between the unconstrained lenders' supply at the rate of return implied by the time 1 and time 2 prices of currency and the constrained borrowers' demand, $D^{\prime}$, at this same rate of return. Equation (B2) expresses equality between the supply of and the demand for currency at $t \geq 2$, while (B3) is the $t=1$ government budget constraint.

To show that these equations have a solution, we divide (B1) by (B2) to get

$$
1 / R(1)=\left\{S[R(1)]-D^{\prime}[R(1)]\right\} /[S(1)-D(1)]
$$

where $R(1)=p(2) / p(1)$. Given our assumptions, equation (B4) has a unique solution denoted $\tilde{R}(1)$. [That any $R(1) \geq 1$ is not a solution follows from $D^{\prime}(1)<D(1)$ and from the fact that $S(R)-D^{\prime}(R)$ is increasing in $R$.] Equation (B4) implies that $S[\tilde{R}(1)]-D^{\prime}[\tilde{R}(1)]>S(1)-D(1)$, which by equation (B3) implies that the initial price level is lower under this constraint on borrowers at $t=1$ than when there is no constraint.

The individuals affected by whether or not such a temporary credit control is imposed at $t=1$ are those present in the economy at $t=1$. The control helps the old at $t=1$ but hurts the lenders of generation 1. It may either help or hurt the borrowers of generation 1 . 